\title{
Generalized beam-spring model for predicting elastic behavior of partially composite concrete sandwich wall panels
}

\author{
Salam Al-Rubaye \\ Utah State University \\ Taylor Sorensen \\ Brigham Young University - Provo, tsorensen@byu.edu \\ Robert J. Thomas \\ Clarkson University \\ Marc Maguire \\ Utah State University
}

Follow this and additional works at: https://scholarsarchive.byu.edu/facpub

Part of the Structural Engineering Commons

\section{Original Publication Citation}

Al-Rubaye, S., Sorensen, T., Thomas, R., Maguire, M. (2019). “Generalized Beam-Spring Model for Partially Composite Concrete Sandwich Wall Panels." Engineering Structures.

\section{BYU ScholarsArchive Citation}

Al-Rubaye, Salam; Sorensen, Taylor; Thomas, Robert J.; and Maguire, Marc, "Generalized beam-spring model for predicting elastic behavior of partially composite concrete sandwich wall panels" (2019). Faculty Publications. 5516.

https://scholarsarchive.byu.edu/facpub/5516

This Peer-Reviewed Article is brought to you for free and open access by BYU ScholarsArchive. It has been accepted for inclusion in Faculty Publications by an authorized administrator of BYU ScholarsArchive. For more information, please contact ellen_amatangelo@byu.edu. 


\title{
Generalized beam-spring model for predicting elastic behavior of partially composite concrete sandwich wall panels
}

\author{
Salam Al-Rubaye ${ }^{\mathrm{a}, \mathrm{b}}$, Taylor Sorensen ${ }^{\mathrm{a}}$, Robert J. Thomas ${ }^{\mathrm{c}}$, Marc Maguire ${ }^{\mathrm{a}, *}$ \\ ${ }^{a}$ Department of Civil and Environmental Engineering, Utah State University, Logan, UT 84322-4110, USA \\ ${ }^{\mathrm{b}}$ Department of Civil Engineering, Tikrit University, Salahuldean, Iraq \\ ${ }^{\mathrm{c}}$ Department of Civil and Environmental Engineering, Clarkson University, Potsdam, NY 13699-5710, USA
}

\section{A R T I C L E I N F O}

\section{Keywords:}

Beam-spring

Composite action

Composite shear connector

Concrete

Insulation

Sandwich wall panel

\begin{abstract}
A B S T R A C T
Partially composite sandwich wall panels (SWP) have been used in the construction industry for at least twenty years. Currently there is limited codified guidance for designers of partially composite concrete SWP, but they are being designed safely and routinely. Design is often guided by the composite connector manufacturers who sell proprietary composite connectors often using a variation of truss-type matrix methods for prediction of elastic behavior of SWPs. The purpose of this paper is to quantify the accuracy of such a model in a uniform manner by developing a generalized version of these matrix models called the beam-spring model (BSM). The primary benefits of the model are its simplicity and versatility making it suitable for design and variations of this model are already in use today. Its accuracy was established in this paper by comparing to 51 specimens from the literature and found to be similar to that of other methods related to strength and cracking of concrete members in the literature. These results indicate that this BSM, or the very similar methods that are already standard practice, provides an adequately safe elastic analysis. On average, the BSM predicted cracking load within $2 \%$ with a coefficient of variation (COV) of $7 \%$, out-of-plane panel stiffness within $3 \%$ with a COV of $17 \%$, and cracking deflection within $2 \%$ with a COV of $18 \%$. These results also indicate that the United States precast industry's use of $7.5 \sqrt{f_{c}^{\prime}}$ for predicting the cracking moment is acceptable for partially composite precast panels. A parametric study performed with the BSM presents several different design situations and can be used as a rudimentary design tool for preliminary behavior and arbitrary connectors.
\end{abstract}

\section{Introduction}

Concrete and rigid foam composite sandwich wall panel (SWP) construction has become a popular building option in response to increasingly stringent energy codes requiring continuously insulated building envelopes. Sandwich wall panels consist of a layer (or wythe) of insulation sandwiched between two wythes of concrete. Design of SWPs is often based on assumptions or empirical testing of varying degrees of composite action between concrete wythes [1]. Fig. 1 shows typical strain distributions in non-composite, partially composite, and fully composite SWPs. Although full-composite action is reportedly easily achieved at the ultimate limit state using a variety of different sandwich wall panel connectors [2], full-composite action is rarely achieved in the elastic range prior to cracking because it requires significant penetration of the insulating wythe with solid concrete, significantly reducing overall thermal efficiency $[1,3]$.

Accurate prediction of elastic stresses and deformations is crucial in the design of SWPs to prevent cracking and limit second order effects [4] since post-cracking deformation behavior is poorly understood [5]. Several techniques and matrix methods have been developed by researchers in the past to assist in predicting SWP deformations ([6-11]), each varying in scope, complexity, and accuracy. Recent research has focused on understanding SWP behavior with respect to various load types present in a building structure. Research by $([5,10])$ recently investigated the full load-deformation behavior of cladding walls through complex iterative procedures. Other research has looked at behavior of SWPs under axial loading [11], while others have investigated thermal deformations $([12,13])$, concentrated loading $([14,15])$ and novel treatments [16]. The current state-of-practice is limited to elastic analysis and design in most cases [4]. This paper investigates a simple but general matrix model that can accurately predict the load and deflection at cracking in partially composite concrete sandwich wall panels, variations of which are being used today for design, even though it resides outside of any codified or recommended

\footnotetext{
* Corresponding author.

E-mail addresses: taylor.sorensen@aggiemail.usu.edu (T. Sorensen), rthomas@clarkson.edu (R.J. Thomas), m.maguire@usu.edu (M. Maguire).
} 
a)

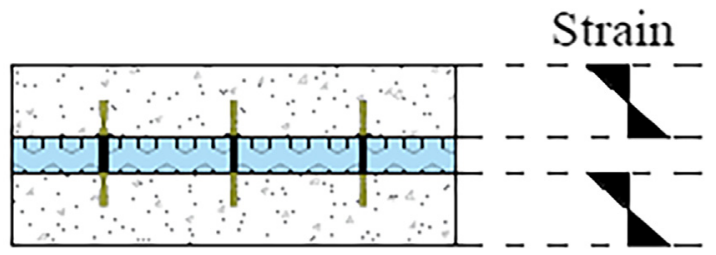

b)

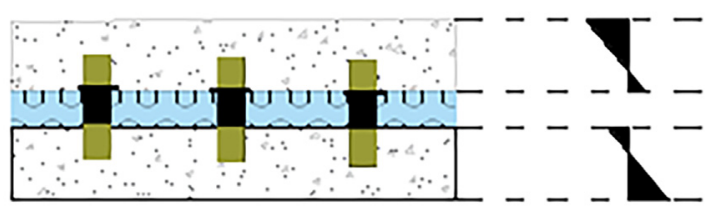

c)

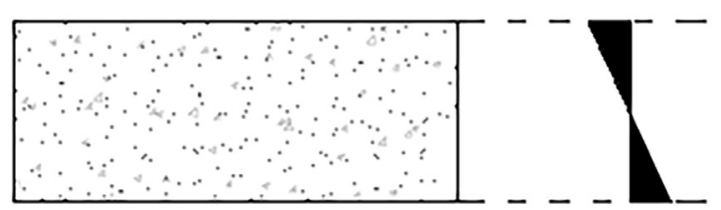

Fig. 1. Strain distributions in (a) non-composite, (b) partially composite, and (c) fully composite SWPs.

practice documents. This paper aims to provide context to this method for practicing engineers and those that use similar methods by quantifying accuracy and investigating suitability of the method for design and analysis.

This is not the first matrix method to be created for this or similar purposes. For example, the concept presented here has been around since the 1980s in multi-wythe masonry [17]. Newmark et al. [18] first investigated the problem of incomplete interaction in composite steel beams. Most partially composite SWP models today are based, in some manner, on Newmark's 1951 analysis. A few have created matrix models based on a modified truss analogy to predict midspan deflections such as in $[19,20]$. Others, such as Teixeira et al. [21], have used a similar model utilizing beams and springs. Most were calibrated to large-scale data based upon previous testing, making the models empirical and limiting the scope of their applicability. Olsen and Maguire [22] noted that several shear connector manufacturers use variations of matrix modeling to predict the percent composite action on a case-bycase basis. These matrix models are based on a truss analysis. Most use a Vierendeel (shear) truss for pin-type connectors, though some with angled connectors utilize angled truss elements [20]. The models were all created for specific situations, connectors, or sets of circumstances with very specific limitations, however. Manufacturers then report the percent composite action to the engineer for design purposes. Olsen and Maguire [22] demonstrated the application of a new model, the beam spring model (BSM), to the problem of partially composite concrete SWPs in an effort to provide the engineer with a generalized method to predict percent composite action when shear test results are available.

Most elastic models for SWP analysis are used for prestressed SWP design where cracking is highly limited in both the transverse and longitudinal direction so the required linear elastic assumptions will be met. These matrix models and other elastic models can be used for sitecast tilt-up construction as well since they are generalized and based on material properties and mechanics if cracking can be controlled in a manner that allows an elastic analysis. Data has been published regarding its use for predictions of both precast/prestressed and reinforced panels as is found in reference [1,2,22-24]. However, the tiltup industry does not prestress, and often has cracking for various reasons $[25,26]$ making the use of an elastic model improper unless additional care and precautions against cracking are made.

Details of how connector manufacturers design SWPs with a matrix model vary between manufacturers just as the geometries and materials of each proprietary connector varies. The models in the literature cited previously have used similar principles with some variation, but no general model suitable for design yet exists. Furthermore, the accuracy of such methods is not well-established in the literature. This paper presents a compilation of elastic large-scale test data from those seven research programs containing 51 large-scale SWPs and three research programs for component shear tests of wythe connectors.

This paper proposes a generalized model of those matrix models presented previously- a model based completely on measured material properties that can be determined and utilized for accurate prediction of load and deflection at cracking for a sandwich wall panel with partial composite action. The major advantages of the proposed model over other models are that it is the first generalized model shown to be applicable to any shear connector type and panel configuration, and that it is not only robust, but is straightforward and user-friendly.

The objectives of this paper are to:

1. Provide the framework for and demonstrate application of the BSM to the problem of partially composite concrete and rigid foam SWPs;

2. Validate the BSM by comparing model results to large-scale experimental data;

3. Perform a parametric analysis to elucidate the effects of connector shear stiffness, connector distribution, length of the panel, and panel configuration on the percent composite action in concrete SWPs; and

4. Describe percent composite action as a function of the connector stiffness for common connector distributions to be used as a simplified preliminary design or analysis tool based on the BSM.

\section{BSM description}

The Beam Spring Model (BSM) is a simple approach using only beam and spring elements with appropriate material values, boundary conditions, and shear connector stiffness. For example, consider the SWP configuration shown in Fig. 2. A BSM of this SWP is shown in Fig. 3, where all connectors are replaced by linking elements (springs) perpendicular to the panel face and the concrete wythes are replaced by two-dimensional beam elements. The input shear stiffness, $K_{E}$, of each linking element is the summation of shear stiffness of the connectors in that row, which is determined experimentally using various shear tests $[6,23,27]$ for the appropriate combination of insulation type, thickness and connector type. In this manner, the insulation type can also be incorporated, lumped into the shear stiffness. If the designer wants to use values with insulation bonded to the concrete or with bond removed, those values are available in the literature [6].

There is, currently, no standard or even well-accepted manner of connector shear testing, however double shear tests (for example see Fig. 4) like those performed in [6] and [23] have been shown to produce material properties that can be used to predict large-scale behavior [1]. Furthermore, a standard for such testing is currently being developed by the Precast/Prestressed Concrete Institute that will make this shear test data ubiquitous and easily compatible with the BSM, facilitating its use.

The purpose of using a discrete spring element is to facilitate generalized design such that any connector can be input with its shear deformation behavior. Some connector manufactures have axial trusslike connectors (NU or X in Fig. 5) and have used truss elements to model their connectors [20]. Because connectors can be of highly variable geometry, the goal of the BSM is to provide a technique that is independent of connector geometry and relies on generalized shear deformation behavior (Fig. 6) for an arbitrary connector, lumping all shear force and deformation at the discrete link element location.

The axial stiffness (perpendicular to the panel face) of the linking elements should be based on the axial stiffness of the connector (currently obtained from ASTM E488 [29] or ICC AC320 [30]), the tributary area, and stiffness of the foam. The authors quickly determined 

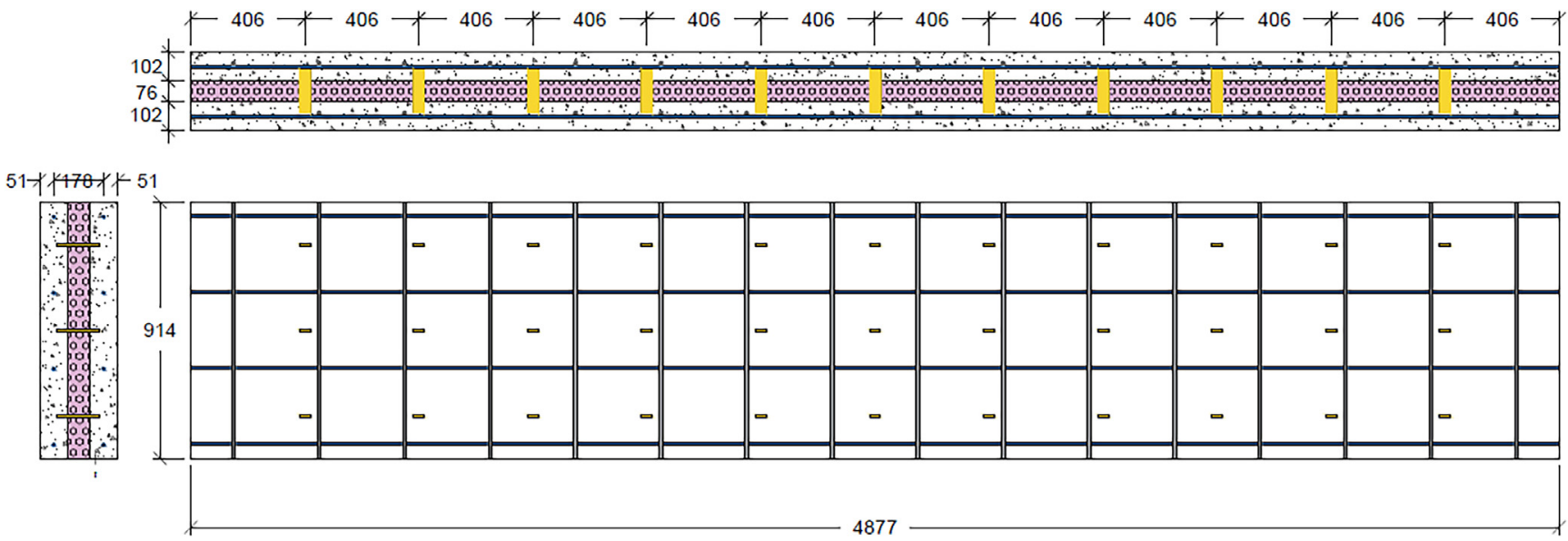

Fig. 2. Representative D panel and Its BSM (all dimensions are in $\mathrm{mm}$ ).

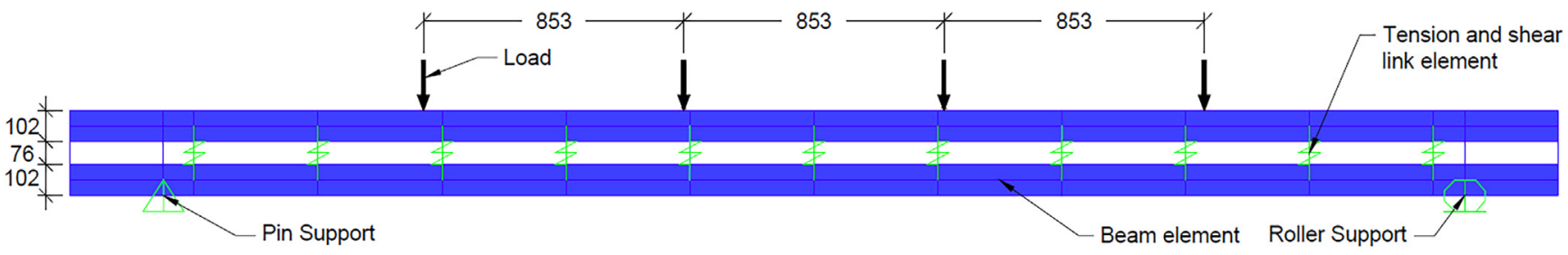

Fig. 3. BSM representation of SWP from Fig. 2 (all dimensions are in $\mathrm{mm}$ ).
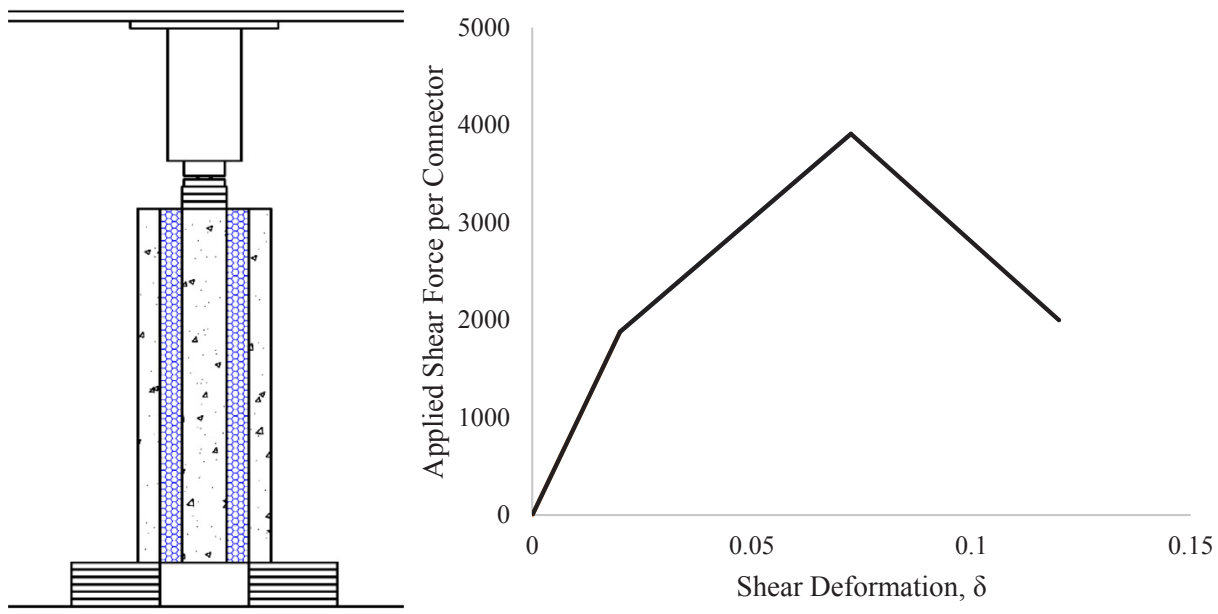

Fig. 4. Double shear test setup (left) and example resultant load-slip plot (right) used to determine connector stiffness. Adapted from [22].

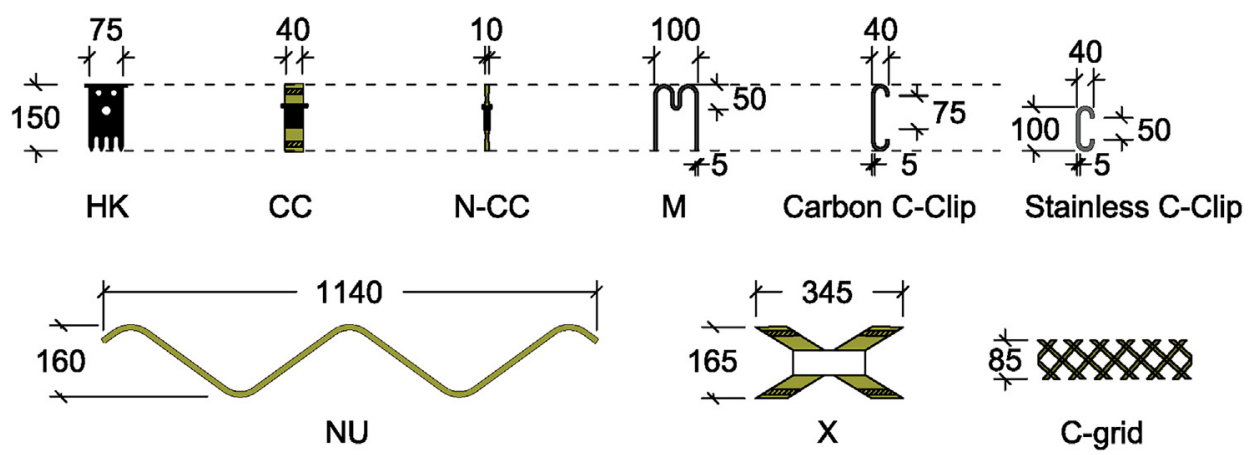

Fig. 5. Connectors details adapted from $[1,5,28]$ (all dimensions are in $\mathrm{mm}$ ). 

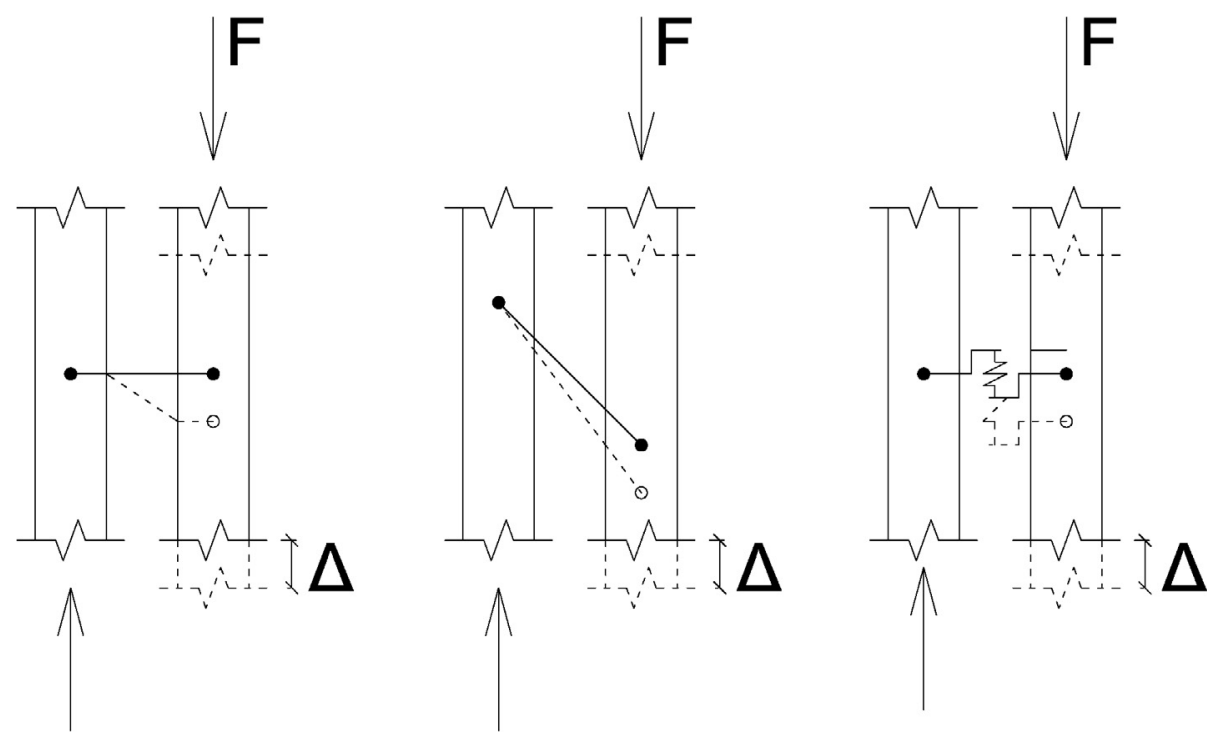

Fig. 6. Generalization of arbitrary connector shear deformation into shear link element.

Table 1

Panel details for experiments from literature.

\begin{tabular}{|c|c|c|c|c|c|c|c|c|c|}
\hline Panel & $\begin{array}{l}\text { Config. } \\
(\mathrm{mm})\end{array}$ & $\begin{array}{l}\text { Width } \\
(\mathrm{mm})\end{array}$ & $\begin{array}{l}\text { Span } \\
(\mathrm{mm})\end{array}$ & Foam type & Connector type Fig. 5) & $\begin{array}{l}\text { Connector Stiffness } \\
(\mathrm{kN} / \mathrm{mm})\end{array}$ & $f_{c}^{\prime}(\mathrm{MPa})$ & Reinforcement Type & \# of Samples \\
\hline A2 [1] & $76-102-76$ & 1220 & 4570 & XPS & A & 20.66 & 72 & Prestressing & 1 \\
\hline A4 [1] & $76-102-76$ & 1220 & 4570 & XPS & A & 20.66 & 72 & Prestressing & 1 \\
\hline $\mathrm{BC} 1[1]$ & $102-76-102$ & 910 & 4270 & XPS & $\mathrm{X} \& \mathrm{CC}$ & $3.33 / 35.90$ & 64 & Mild & 1 \\
\hline BC2 [1] & $102-76-102$ & 910 & 4270 & XPS & $\mathrm{X} \& \mathrm{CC}$ & $3.33 / 35.90$ & 55 & Mild & 1 \\
\hline D1 [1] & $102-76-102$ & 910 & 4270 & XPS & $\mathrm{D}$ & 16.60 & 64 & Mild & 1 \\
\hline D2 [1] & $102-76-102$ & 910 & 4270 & XPS & $\mathrm{D}$ & 16.60 & 55 & Mild & 1 \\
\hline Salmon et al. [34] & $64-76-64$ & 2438 & 9144 & EPS & \#3 Nu V1 & 70.05 & 43 & Prestressing & 2 \\
\hline PCS1 [35] & $76-51-76$ & 813 & 3048 & EPS & Stainless C-Clip & Nonlinear [28] & 57 & Prestressing & 3 \\
\hline PCS2 [35] & $76-51-76$ & 813 & 3048 & EPS & C-Grid & 21.19 & 58 & Prestressing & 3 \\
\hline PCS3 [35] & $76-51-76$ & 813 & 3048 & EPS & C-Grid & 21.19 & 58 & Prestressing & 3 \\
\hline PCS4 [35] & $76-76-76$ & 813 & 3048 & XPS & $\begin{array}{l}\text { Carbon } \\
\text { C-Clip }\end{array}$ & Nonlinear [28] & 61 & Prestressing & 3 \\
\hline PCS5 [35] & $76-76-76$ & 813 & 3048 & XPS & CC & 3.33 & 61 & Prestressing & 3 \\
\hline PCS6 [35] & $76-76-76$ & 813 & 3048 & XPS & C-Grid & $12.43^{*}$ & 60 & Prestressing & 3 \\
\hline PCS7 [35] & $76-76-76$ & 813 & 3048 & XPS & CC & 3.33 & 61 & Mild & 3 \\
\hline PCS8 [35] & $76-76-76$ & 813 & 3048 & ISO & $\mathrm{CC}$ & 5.25 & 61 & Prestressing & 2 \\
\hline TS1 [35] & $152-51-76$ & 406 & 3048 & XPS & $\mathrm{N}-\mathrm{CC}$ & 2.10 & 34 & Mild & 3 \\
\hline TS2 [35] & $76-51-76$ & 406 & 3048 & XPS & $\mathrm{CC}$ & 3.85 & 34 & Mild & 3 \\
\hline $\mathrm{PtEG}_{2}[36]$ & $76-51-76$ & 813 & 3048 & EPS & C-Grid & 21.19 & 48 & Prestressing & 3 \\
\hline RtXN [36] & $76-51-76$ & 813 & 3048 & XPS & \#3 Nu V5 & 70.05 & 34 & GFRP & 3 \\
\hline PtXN [36] & $76-51-76$ & 813 & 3048 & XPS & \#3 Nu V5 & 70.05 & 34 & Prestressing & 3 \\
\hline $\operatorname{RtXX}[36]$ & $76-51-76$ & 813 & 3048 & XPS & $\mathrm{X}$ and $\mathrm{CC}$ & $3.85 / 15.76$ & 41 & Mild & 3 \\
\hline P-NCF [37] & $76-51-76$ & 2438 & 4877 & EPS & $\begin{array}{l}\text { Concrete section and pin } \\
\text { connector }\end{array}$ & Concrete Section & 41 & Prestressing & 1 \\
\hline $\begin{array}{l}\text { Floor Panel C } \\
\text { [38] }\end{array}$ & $76-76-102$ & 1219 & 7722 & XPS & \#3 Nu V5 & 70.05 & 40 & Prestressing & 1 \\
\hline
\end{tabular}

that the generalized BSM is not sensitive to the axial stiffness of the linking element, and so its selection is of little importance to the out-ofplane behavior where shear stiffness dominates. The beam elements are then assigned the individual gross properties of each wythe (such as cross-sectional area, $A_{w y}$, and modulus of elasticity, $E_{c}$ ) and are separated by a distance equal to the distance between the centroids of the wythes. Support conditions will be modeled as a pin (no translation, free rotation) and roller (free longitudinal displacement, free rotation). The boundary conditions between linking elements and beam elements include fixed translation and fixed rotation. In this paper, the BSM analysis is performed using a commercial matrix analysis software package, though it can be run in any matrix analysis software package.

Any load pattern can be applied to the BSM and panel geometry can be appropriately modeled. For the validation section below, the panels were loaded with the appropriate point or pressure loads. Panel cracking occurs when stresses equal the modulus of rupture. The modulus of rupture is assumed to be $7.5 \sqrt{f_{c}^{\prime}}$ in accordance with standard precast practice [4]. This is different than is assumed for slender walls in the ACI code [31], which uses $5 \sqrt{f_{c}^{\prime}}$, based on the results from testing performed in the 1980s on tilt-up wall panels [32,33]. In using this model in practice, the appropriate limiting tension stress may be used. Some of the perceived benefits of the generalized BSM are:

1. Versatility: The generalized BSM can handle any geometry, boundary condition, connector distribution, connector type, or combination thereof with ease. The generalized BSM can handle discrete connectors as well as continuous connectors if they are discretized into small segments.

2. Simplicity: The generalized BSM requires only two type of elements and three material properties, and can be run in any matrix analysis 

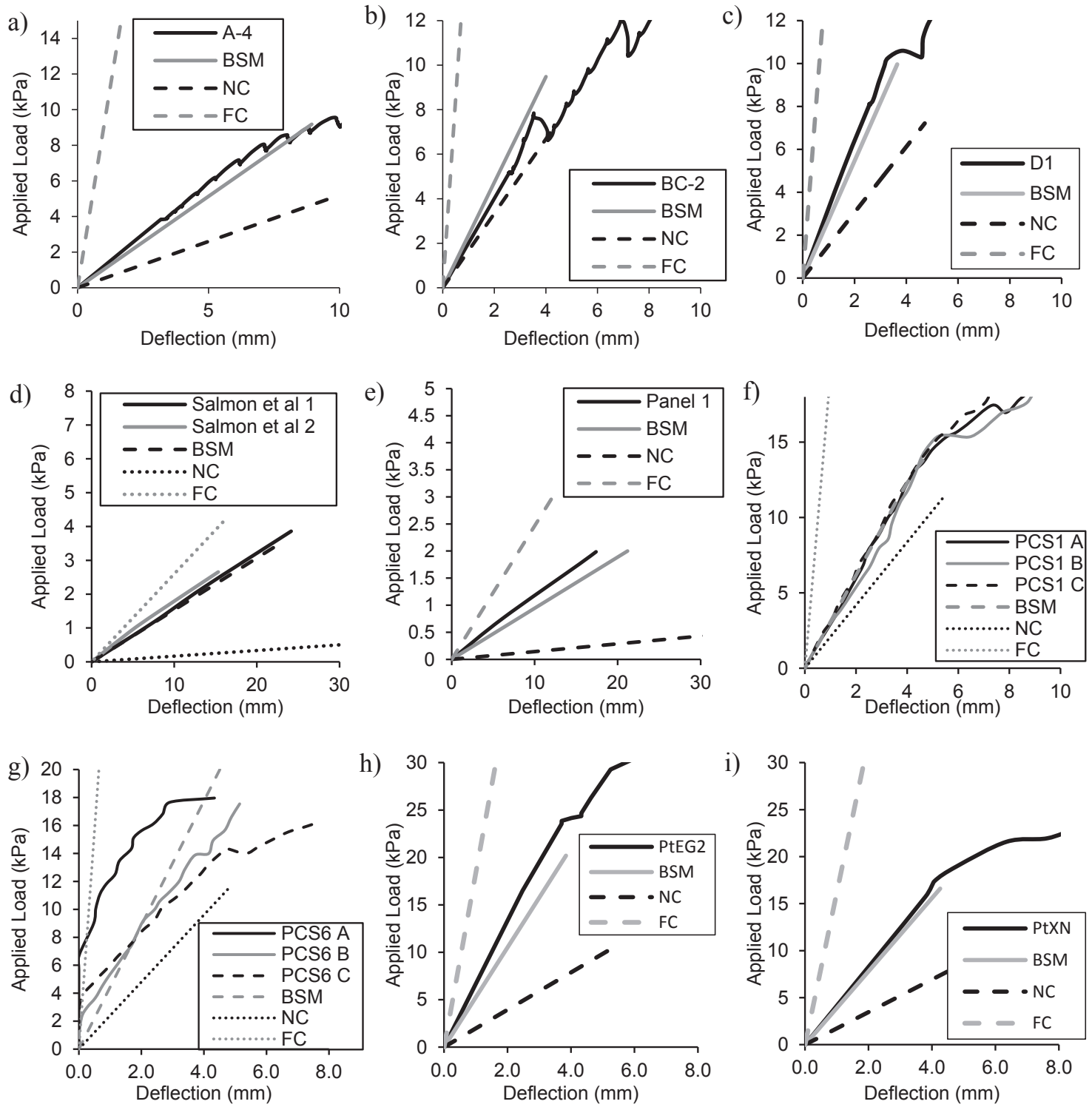

Fig. 7. Comparison between the experiment data and BSM prediction.

software package.

3. Accuracy: The primary intent of this paper is to establish the accuracy of the generalized BSM, but manufacturers and designers have successfully employed BSM variants in practice already.

\section{Experimental validation}

Although published large-scale and component testing data for sandwich wall panels is relatively scarce compared to other member types like beams, the BSM was used to predict the behavior in a variety of large-scale experiments that have been reported elsewhere in the literature, comparing predicted load and deflection at cracking to the actual experimental results. Table 1 lists the specifications for 51 panel designs tested and reported in the literature, including a variety of different lengths, configurations, and reinforcement and connector types, used to validate the BSM. Salmon et al. published experimental results for two panels in 1997 [34]. Panel PCS 1 through PCS9 and TS1 and TS2 came from experiments conducted by Naito et al. in a 2011 study [35]. PtEG2, RtXN, PtXN, and RtXX panels were tested by Trasborg in 2014 [36]. Note that Trasborg reported the average of the three specimens by averaging the measured load at each measured support deflection. The connector shear stiffness data were obtained from push- off tests performed by previous researchers $[6,23,27]$. Fig. 5 shows the different connector types used in these panels.

Comparisons between generalized BSM predictions and experimental results for the load-deflection of select panels from Table 1 are shown below in Fig. 7. The generalized BSM was used to predict the cracking moment, $M_{c r}$ and deflection, $\Delta$, given the loads applied in each reference. The load is reported as a pressure load, converted using the total vertical load divided by the tributary area in order to maintain consistent units across experiments and references. These results are plotted with the experimental results and theoretical predictions for non-composite (NC) and fully-composite (FC) predictions to provide context. The last point in each prediction curve represents when the panel achieves $7.5 \sqrt{f_{c}^{\prime}}$. In Fig. 7 the experimental data is zoomed in only on the elastic, pre-cracked region.

Table 2 shows the ratio of the actual test results and compares them to the BSM predicted values for cracking (assuming $7.5 \sqrt{f_{c}^{\prime}}$ ) and stiffness (assuming $57,000 \sqrt{f_{c}^{\prime}}$ ). The BSM had a tendency to underestimate cracking, which may be attributed to manufacturing imperfections or installation of the foam and connectors, which heavily influence the accuracy of connector stiffness values. Also, in all cases the large-scale tests allowed concrete to bond to the insulation. This adhesion is known 
Table 2

Comparison of experimental (Exp.) and BSM cracking load and deflection for experiments from literature.

\begin{tabular}{|c|c|c|c|c|c|c|}
\hline \multirow[t]{2}{*}{ Panel } & \multicolumn{2}{|c|}{$\begin{array}{l}\text { Cracking load } \\
(\mathrm{kPa})\end{array}$} & \multicolumn{2}{|c|}{ Stiffness $\left(\mathrm{kN}^{*} \mathrm{~m}^{2}\right)$} & \multicolumn{2}{|c|}{$\begin{array}{l}\text { Cracking deflection } \\
(\mathrm{mm})\end{array}$} \\
\hline & Exp. & $\begin{array}{l}\text { Exp./ } \\
\text { BSM }\end{array}$ & Exp. & Exp./BSM & Exp. & $\begin{array}{l}\text { Exp./ } \\
\text { BSM }\end{array}$ \\
\hline A-2 & 7.45 & 1 & 6606 & 1.15 & 8.64 & 0.87 \\
\hline A-4 & 9.65 & 1.05 & 6794 & 0.84 & 11.18 & 1.25 \\
\hline BC-1 & 8.62 & 0.87 & 12,202 & 1.17 & 3.05 & 0.74 \\
\hline BC-2 & 7.86 & 0.87 & 6601 & 0.87 & 3.81 & 1 \\
\hline D-1 & 10.55 & 1.01 & 13,095 & 1.09 & 3.56 & 0.93 \\
\hline D-2 & 8.83 & 0.93 & 10,169 & 0.94 & 3.3 & 0.98 \\
\hline $\begin{array}{l}\text { Salmon et al. } \\
{[34]}\end{array}$ & 3.03 & 0.9 & 34,969 & 1.02 & 19.25 & 0.88 \\
\hline PCS1 [35] & 15.03 & 1.03 & 2612 & 0.97 & 5.26 & 1.06 \\
\hline PCS2 [35] & 19.03 & 1 & 4278 & 0.97 & 4.06 & 1.03 \\
\hline PCS3 [35] & 20.79 & 1.1 & 4315 & 1.04 & 4.4 & 1.06 \\
\hline PCS4 [35] & 13.79 & 0.96 & 2067 & 0.8 & 6.1 & 1.2 \\
\hline PCS5 [35] & 15.03 & 1.12 & 2371 & 0.98 & 5.79 & 1.14 \\
\hline PCS6 [35] & 18.27 & 0.91 & 3866 & 0.75 & 4.32 & 1.21 \\
\hline PCS7 [35] & 9.51 & 1 & 2573 & 1.07 & 3.38 & 0.94 \\
\hline PCS8 [35] & 12.92 & 0.93 & 3501 & 1.35 & 3.37 & 0.69 \\
\hline TS1 [35] & 12.55 & 0.89 & 4900 & 1.3 & 1.17 & 0.69 \\
\hline TS2 [35] & 7.72 & 1.01 & 1261 & 1.28 & 2.79 & 0.79 \\
\hline $\mathrm{PtEG}_{2}[36]$ & 23.44 & 1.15 & 5776 & 1.2 & 3.71 & 0.96 \\
\hline RtXN [36] & 10.41 & 0.98 & 2903 & 0.82 & 3.28 & 1.19 \\
\hline PtXN [36] & 15.72 & 0.95 & 3795 & 1.06 & 3.78 & 0.89 \\
\hline RtXX [36] & 9.58 & 1.01 & 2196 & 0.74 & 3.99 & 1.35 \\
\hline P-NCF [37] & 5.86 & 0.98 & 27,625 & 1.04 & 3.81 & 0.94 \\
\hline $\begin{array}{c}\text { Floor Panel C } \\
\text { [38] }\end{array}$ & 5.81 & 0.98 & 21,699 & 1.02 & 15.11 & 0.96 \\
\hline Average & - & 0.98 & - & 1.03 & - & 0.98 \\
\hline $\mathrm{COV}$ & - & 0.07 & - & 0.17 & - & 0.18 \\
\hline
\end{tabular}

to be a variable phenomenon $[6,8]$. The connector shear stiffness input into the BSM in all cases corresponded to the appropriate connector in a certain insulation thickness and with the insulation-concrete bond intact from a double shear test from the literature. In design, it would be more prudent to use shear test values that eliminate or minimize bonding of the concrete to the insulation (i.e. unbonded) [1] unless otherwise recommended by the manufacturer.

However, the average of the measured-to-predicted ratios in Table 2 is exceptionally close to unity at 0.98 with a coefficient of variation (COV) of 0.07 for BSM cracking load predictions, and 1.03 with a COV of 0.17 for panel stiffness (slope of elastic curve) predictions. The cracking-at-deflection prediction is something of a combination of these two, and is predicted with a measured-to-predicted ratio of 0.98 and a COV of 0.18 . The relatively large COV for the stiffness prediction and the cracking deflection prediction suggests that the generalized BSM is less accurate in predicting cracking deflection than cracking load.

To put these BSM statistics into context, several other accepted models for different phenomena are investigated. In the reliability literature, the random variable representing the accuracy of a given model is called the professional factor, and its bias and COV can be calculated from the measured-to-predicted ratio of a given limit state as is done in Table 2. The accuracy of the BSM is similar to other analysis models for structures, like reinforced and prestressed concrete beams and steel members (i.e. for flexure and shear in a concrete beam, the professional factor is 1.02 with COV 0.06 and 1.075 with COV 0.1, respectively [39]). The professional factor parameters from [39] and elsewhere are typically presented for the strength limit state. The professional factor parameters for the service limit states are not as welldocumented in the literature since service is often not considered for reliability analysis. However, these have been used for service reliability calculations in the past $[40,41]$ and other limited research has estimated professional factor average properties for reinforced beam cracking as 1.02 and with $\mathrm{COV} 0.096$ and for the Bischoff effective moment of inertia as 0.96 with COV 0.20 [42].

The research that indicates that $5 \sqrt{f_{c}^{\prime}}$ should be used for the cracking stress of slender tilt-up panels provides a measured-to-predicted ratio of 1.2 with COV of 0.13 [33]. Considering the presented accuracy of the BSM using $7.5 \sqrt{f_{c}^{\prime}}$, this combination is just as justifiable and appropriate for design. It should be noted that the tilt-up panels tested in the $1980 \mathrm{~s}$ $[32,33]$ were taller than the majority of the panels in Table 2 , and if panels of similar geometry were tested, a drop in cracking moment may be observed, but at this time is not known.

\section{Parametric study}

Once the accuracy of the generalized BSM was established, a parametric study was performed to demonstrate the effects of connector distribution, panel length, and connector shear stiffness on composite action in various SWP configurations. Three connector distributions were considered, as shown in Fig. 8: (a) uniformly distributed, with connectors at regular intervals throughout the length of the panel, (b) triangularly distributed, with higher connector density at the panel ends and lower connector density at mid-span, and (c) concentrated, with connectors concentrated only at the panel ends. Fig. 8 also displays the shear stiffness of the panel as a function of distance for each distribution.

The modulus of elasticity and modulus of rupture of the concrete were defined using ACI 318-08 §8.5.1 and Eqs. (9) and (10) [31], resulting in $E=27793 \mathrm{MPa}$ and $\mathrm{f}_{\mathrm{r}}=3.65 \mathrm{MPa}$, respectively, in accordance with the PCI state-of-the-art report [4]. Panels were simply supported and subject to a uniform applied load that would induce the modulus of rupture at any point in the panel. Each analysis was performed per foot panel width. For comparison purposes below, the total stiffness contributed by the connectors is transformed to a stiffness per area for uniform and triangular connectors by multiplying the stiffness of the connector by the total number of connectors and dividing by the total panel area. For connectors concentrated at the ends, the same calculation is made, but the tributary area at the end is used in lieu of the total panel area.

To facilitate comparison between the panels, it was necessary to calculate the degree of composite action achieved in each panel. The degree or percentage of composite action is a value between 0 and 1 , where 0 indicates fully non-composite and 1 indicates fully composite. Fig. 9 shows a visual representation of degree of composite action. The degree of composite action is the ratio of the difference between the actual or predicted value and the perfectly non-composite value, and the difference between the theoretically fully-composite value and the perfectly non-composite value. Degree of composite action was calculated in two ways, one based off of cracking moment and the other based off of cracking deflection as shown in Eqs. (1) and (2) respectively, where the moment of inertias were used to determine degree of composite action for deflections at cracking.

$K_{M c r}=\frac{M_{c r, B S M}-M_{c r, N C}}{M_{c r, F C}-M_{c r, N C}}$

where

$M c r_{B S M}=$ BSM cracking moment of the sandwich panel

$M c r_{N C}=$ theoretical cracking moment of the non-composite sandwich panel

$M c r_{F C}=$ theoretical cracking moment of the fully composite sandwich panel

$K_{d}=\frac{I_{B S M}-I_{N C}}{I_{F C}-I_{N C}}$

where

$I_{B S M}=$ BSM moment of inertia the sandwich panel 

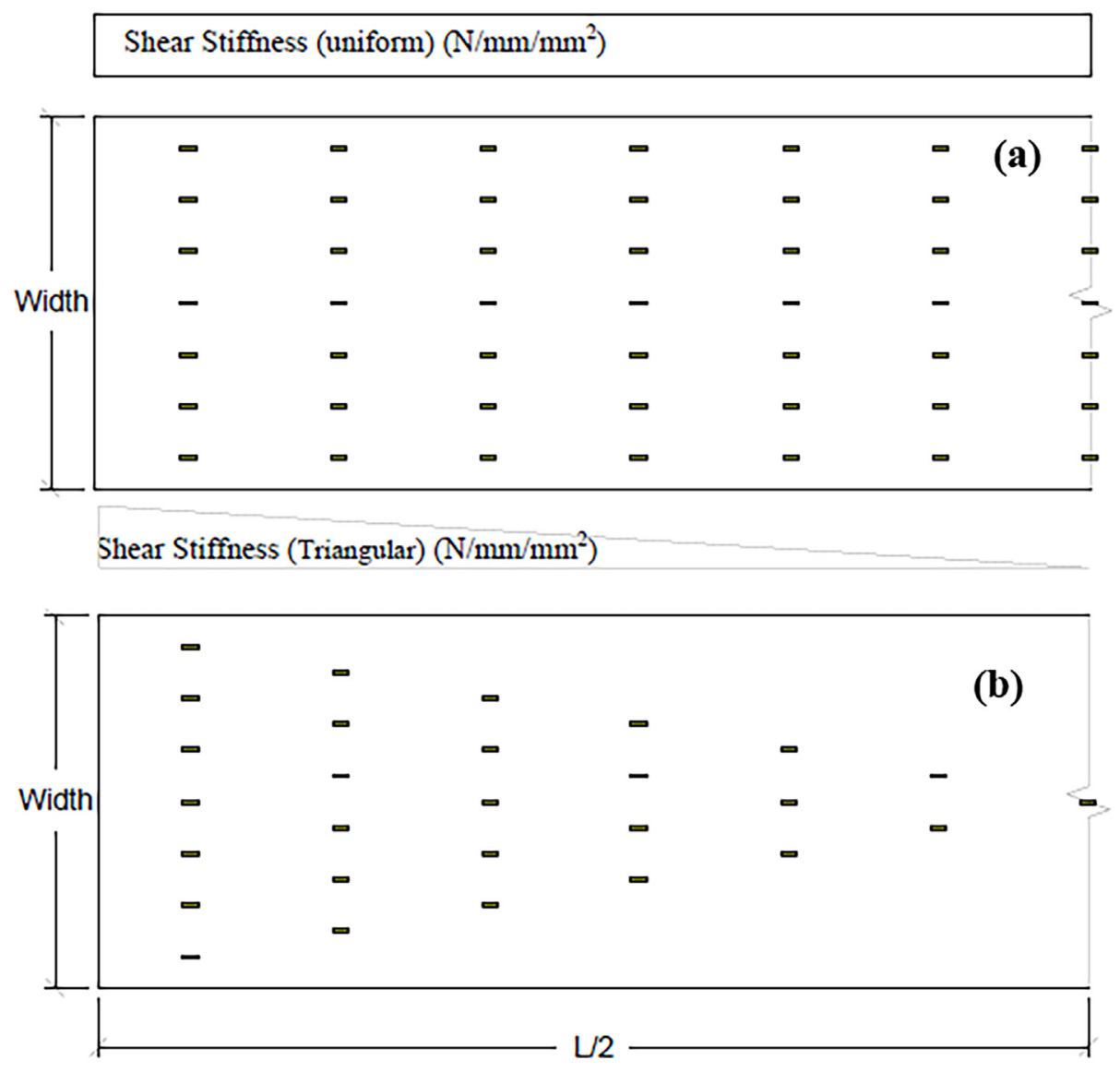

Shear Stiffness (L 2 mped) $\left(\mathrm{N} / \mathrm{mm} / \mathrm{mm}^{2}\right.$ )

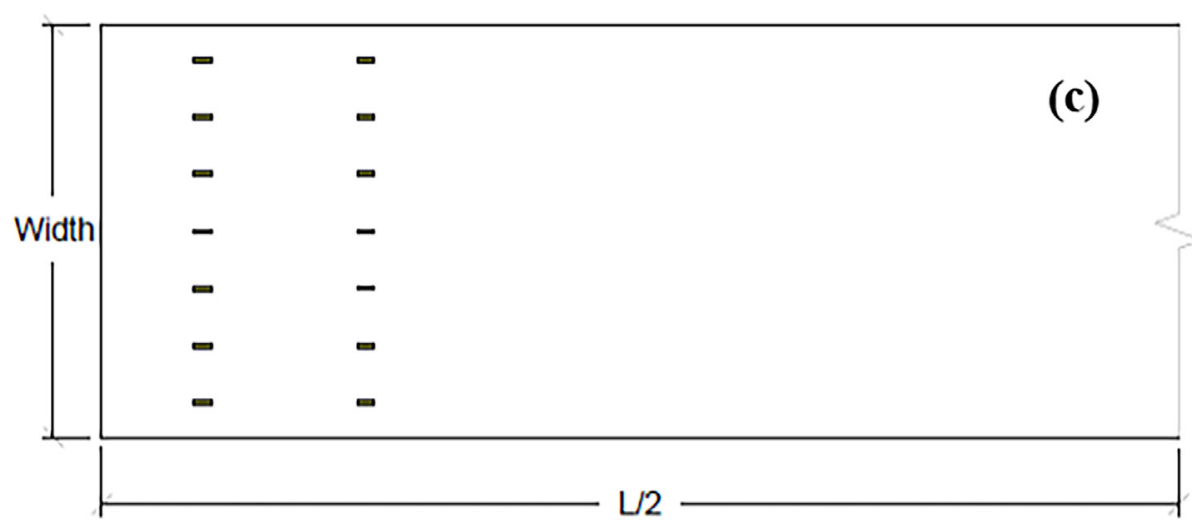

Fig. 8. Connector distributions for parametric study: (a) uniform, (b) triangular, and (c) concentrated.

$I_{N C}=$ theoretical moment of inertia of the non-composite sandwich panel

$I_{F C}=$ theoretical moment of inertia of the fully composite sandwich panel

\subsection{Uniform connector distribution}

Typical results for uniformly-distributed connectors are shown in Fig. 10. This specimen assumed a 76-76-76 configuration, span length of $11,000 \mathrm{~mm}$, and connector shear stiffness of $0.126 \mathrm{~N} / \mathrm{mm} / \mathrm{mm}^{2}$. Stresses in the panel can be found in Fig. 10a and illustrate how the connectors create a "saw tooth" type pattern along the length of the panel as they impart their forces in discrete locations. The connector force vs. location has an hourglass shape as presented in Fig. 10b. One can see the tensile effects generated by what is termed transverse (normal to the panel plane) action noted by several past researchers experimentally and analytically [43-45] which is caused by the free edge at the end of the panel, generating the drop in force in the connector at the end of the span. The maximum tensile (positive) stress due to the bending moment and axial forces is at the connector near to the midspan. There is clearly significant compressive stress generated in the top fiber of the bottom wythe near the ends of the panel which is caused by the large connector forces acting at these locations.

Fig. 11 shows the relationship between panel stiffness and the deflection and cracking degree of composite action achieved in 76-76-76 SWPs, for different panel lengths (in meters). For example, the annotation "D-11-(76-76-76)" represents the curve for composite action determined using deflection for a panel 11-m long and with a 76-76-76 


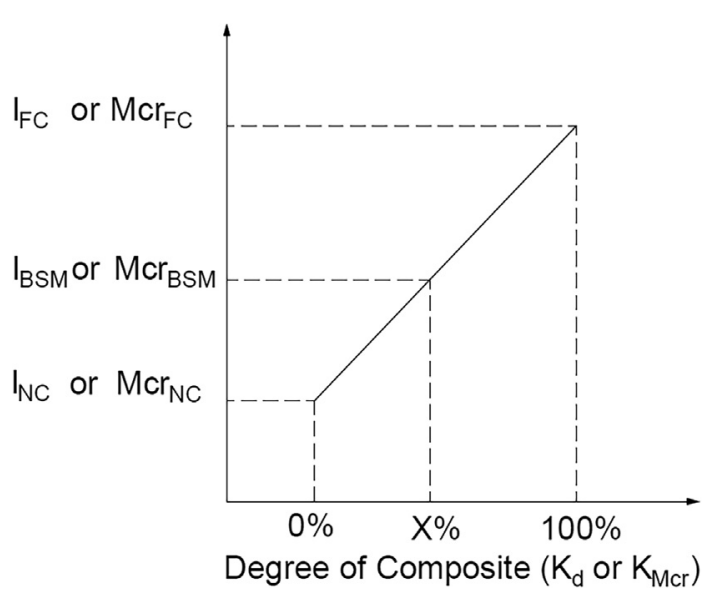

Fig. 9. Visual demonstration of degree of composite action.

panel configuration. Likewise, a "C-11-(76-76-76)" signifies the same except for the composite action determined using cracking instead. As stiffness increases, so does the apparent percent composite action. This also demonstrates that increasing the length of a panel will increase the composite action. This is because the longer a panel is, the more slip will be able to be achieved before the panel will crack. As a result, the connector forces increase since the force exhibited in the connectors is dependent on the deflection in the connector itself.

Fig. 11 can be used as a simplified analysis tool for varying panel lengths and connector stiffness independent of a proprietary connector. For example, consider a 76-76-76 panel that has a length equal to $7.3 \mathrm{~m}$. If the panel would be required to resist a wind load of $2.4 \mathrm{kPa}$ (resulting in an applied moment of $16.01 \mathrm{kN}-\mathrm{m} / \mathrm{m}$ ), the minimum percentage of composite action required for cracking would need to be $38 \%$ to resistance the wind load. Using this value, the minimum stiffness can be determined $\left(0.14 \mathrm{~N} / \mathrm{mm} / \mathrm{mm}^{2}\right.$ in this case) which can then be used to calculate the required spacing and total number of connectors needed for the panel.

\subsection{Triangular connector distribution}

The previous case of uniform connector distribution suggests that the connector forces are approximately triangularly distributed along the half span. As such, a triangular connector distribution may reduce the number of required connectors and provide a more efficient panel design. For the case of triangular connector distribution, the connector

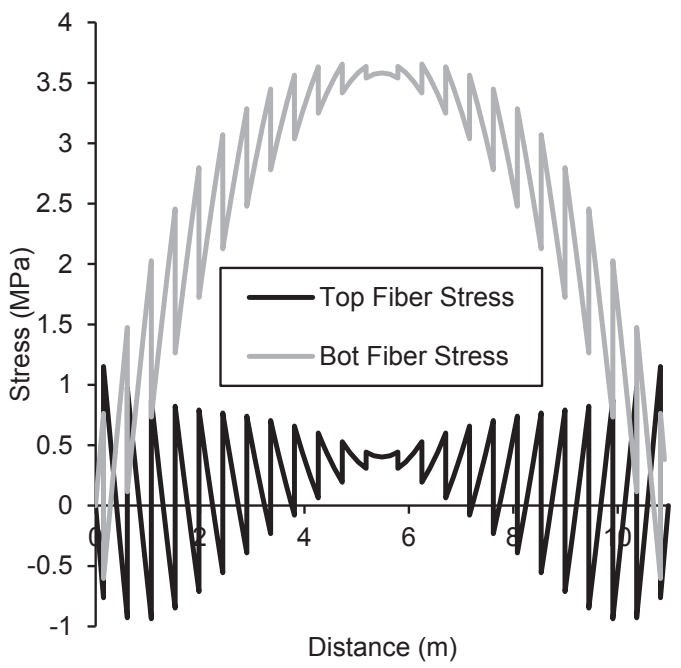

density increases from midspan to the end of the panel as shown in Fig. 8(b). The resulting shear stiffness decreases linearly from its maximum at the end of the panel to zero at midspan.

Fig. 12a shows that the stresses predicted by the generalized BSM for a SWP with a triangular connector distribution follow the same pattern as a uniform connector distribution, but seem to have less distributed tensile stresses. The maximum stress is similar (compare 3.7 MPa ksi in Fig. 8a to 3.7 MPa in Fig. 12a), and the predicted values actually show no compression stresses near midspan due to the connectors. For the purpose of comparison, all of the same panel properties from the previous subsection were used here, only reducing the number of connectors. The connector force shape is essentially triangular for this distribution. Similar to the previous example, there are very large stresses generated in the bottom wythe at the ends of the panel (in excess of what would typically be expected) due to the large connector force couples. Fig. 13 presents composite action as a function of triangularly distributed connector stiffness and panel length.

\subsection{Connectors concentrated at ends}

In the previous section, it was shown that a triangular connector distribution (Fig. 8b) is more efficient than a uniform connector distribution (Fig. 8a). It logically follows that a lumped connector distribution at the location of maximum connector force may also result in an efficient panel design (Fig. 8c). Therefore, the third panel configuration included in the parametric study concentrated all SWP connectors at the ends of a panel. Should this design methodology prove successful, it may allow the addition of connectors near the ends of the panel to be an alternative to enlarging wythe thickness or using higherstrength concrete.

In some cases, designers will specify solid sections in SWPs (such as to satisfy embedment requirements for lifting anchors, to help with stripping and handling, to attain higher composite action, etc.). Inclusion of solid sections can provide increased composite action. By concentrating connectors only at the ends of panels, the same effect is achieved. This model is also similar to a panel that has connectors with significantly higher shear stiffness or solid concrete sections located near the edges of the panel. Sometimes a combination of connectors are used. For example, panel P-NCF from Table 2 had steel pin connectors and solid concrete zones at the ends for handling and stripping. Large solid concrete sections will have a significantly higher shear stiffness than the pin connectors, causing the BSM to work essentially as if there were lumped connectors at the ends. This is also true of a panel that has composite connectors at the ends and non-composite connectors elsewhere.

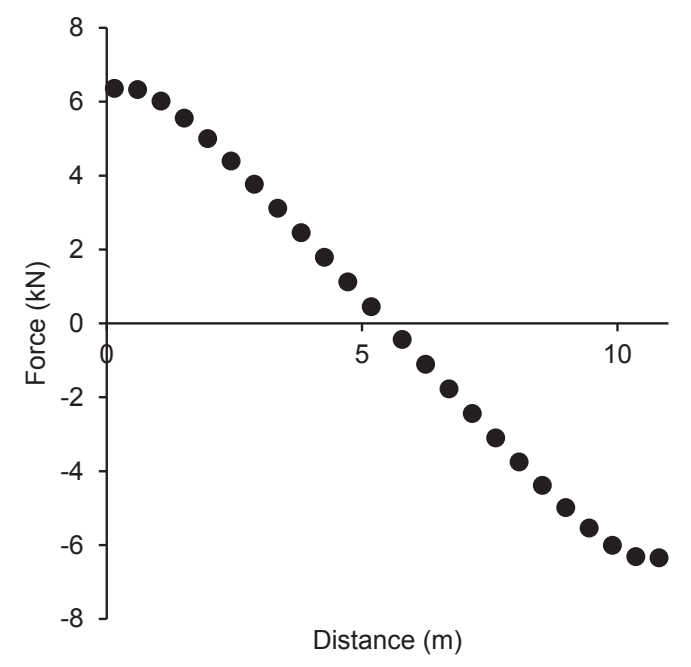

Fig. 10. (a) Stresses of the bottom wythe and (b) connector forces. 

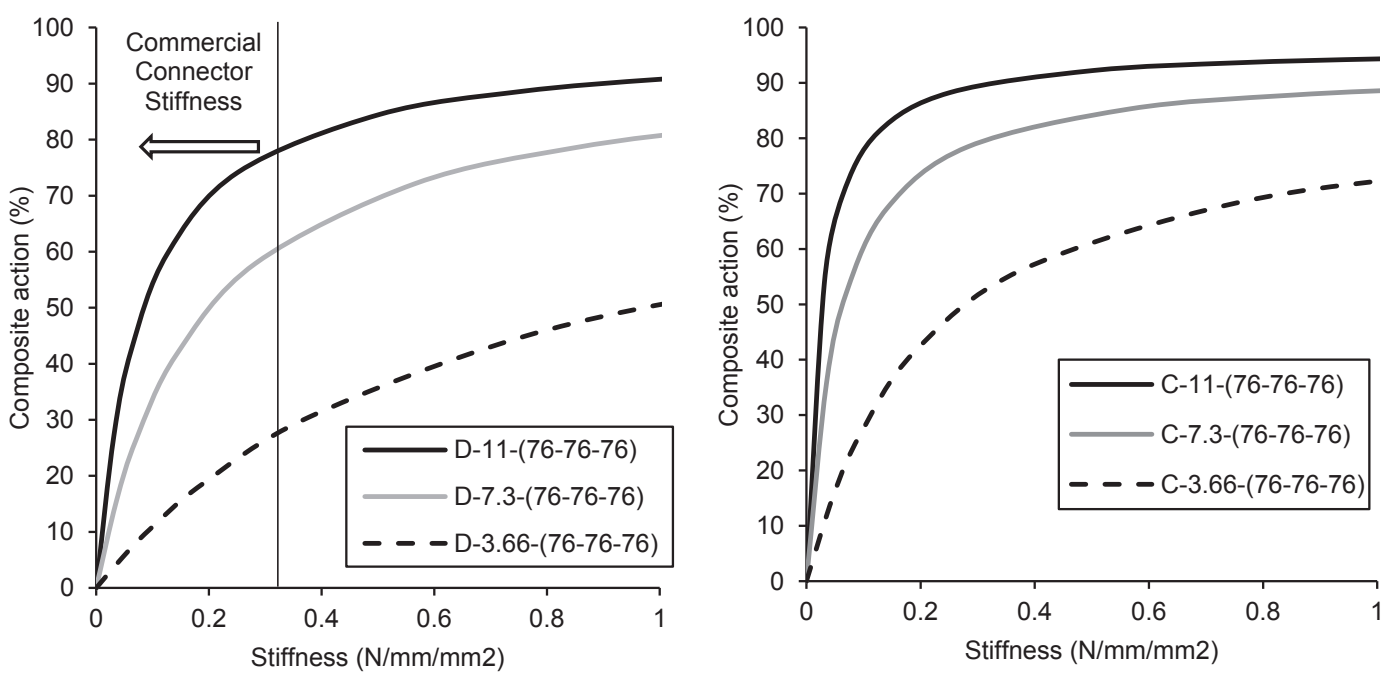

Fig. 11. Percent composite action vs. stiffness for deflection (left) and cracking (right) in 76-76-76 SWP.
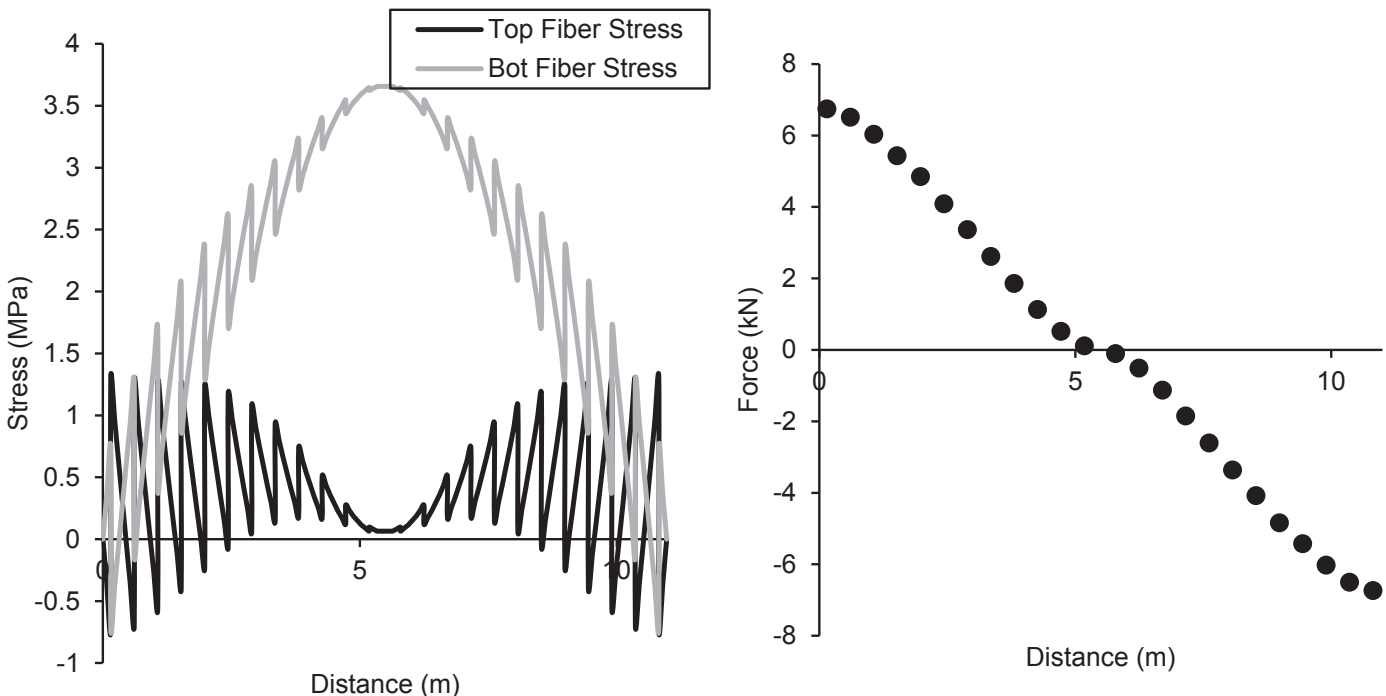

Distance (m)

Fig. 12. Profile of stress (left) and connector forces (right) for SWP with triangular distribution.
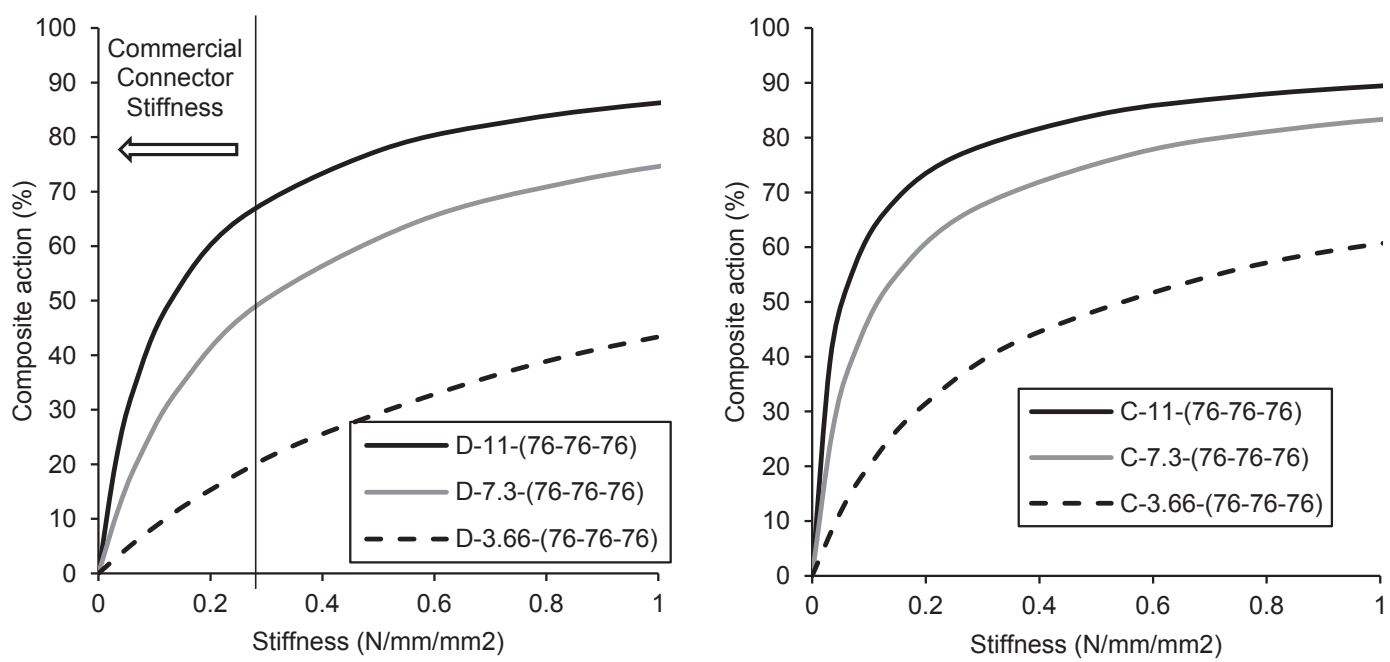

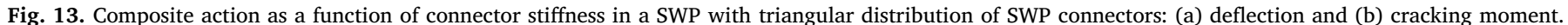



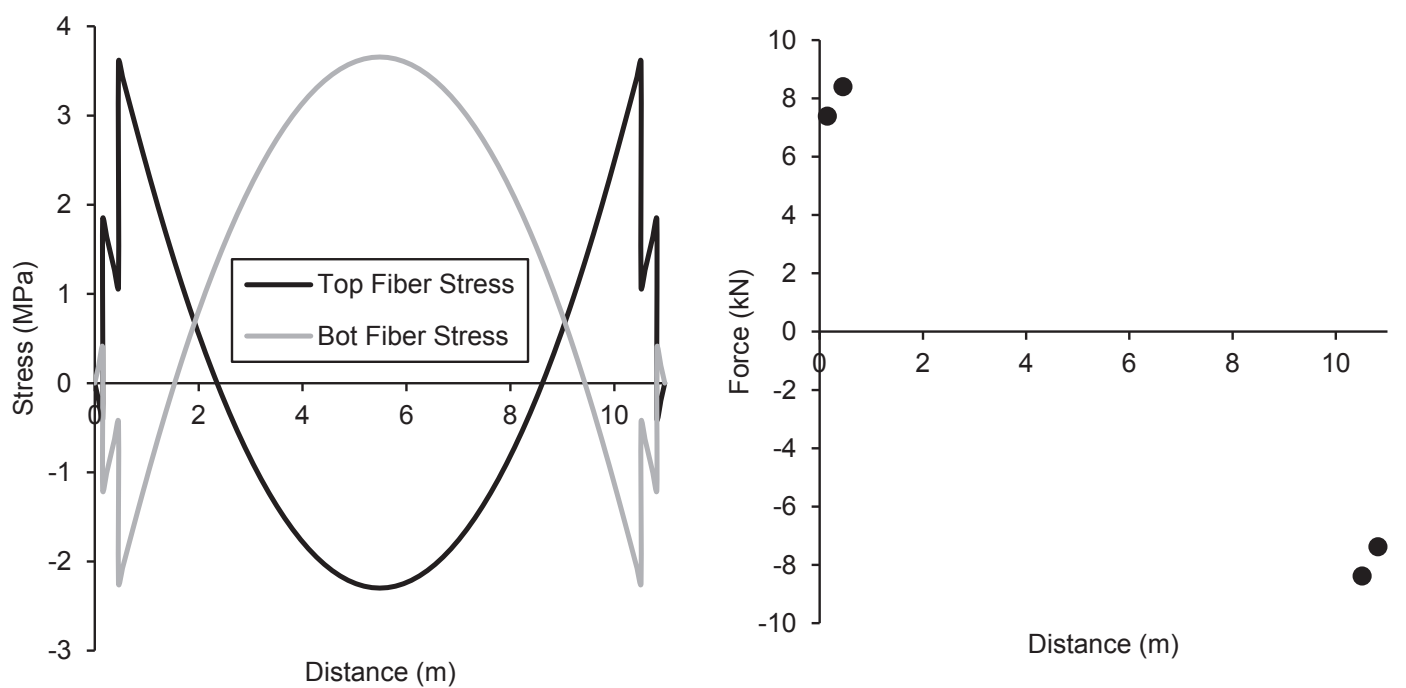

Fig. 14. Stress profile (left) Connector Forces profile (right).
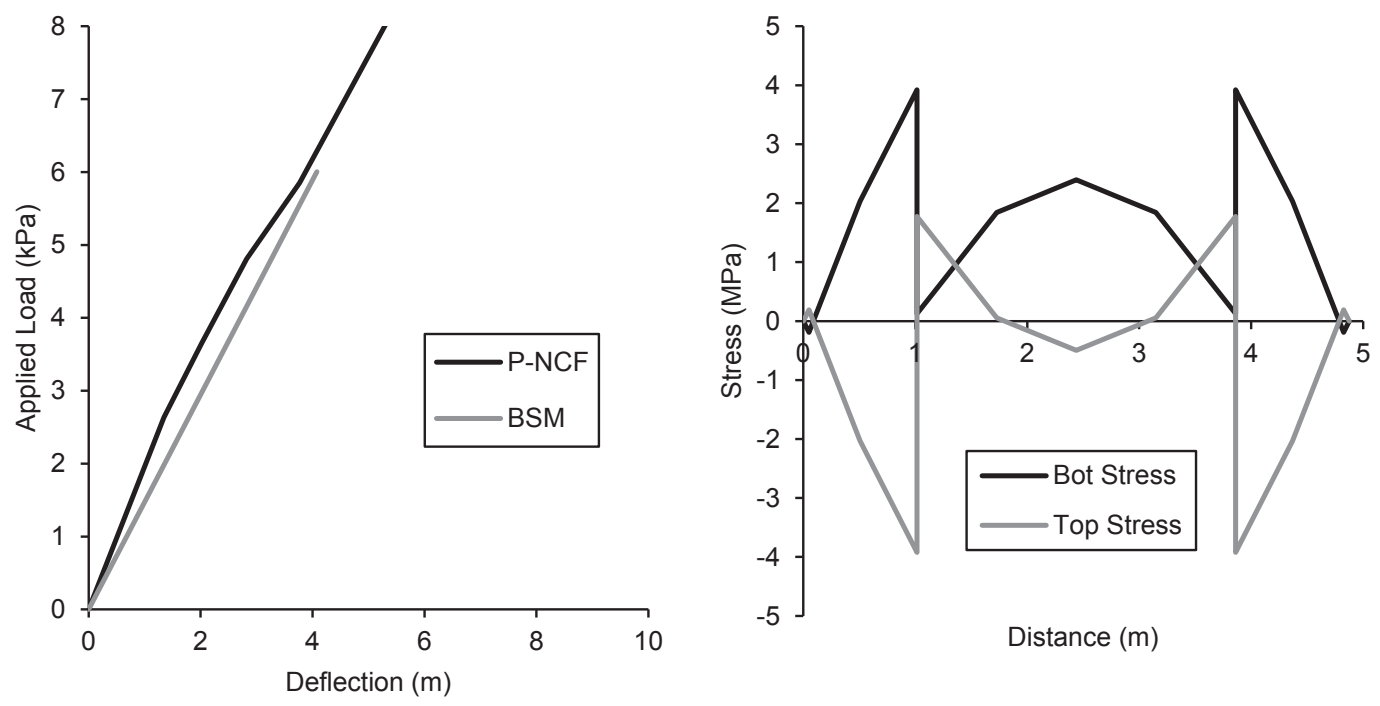

Fig. 15. Panel P-NCF tested by Bush and Stine [37].
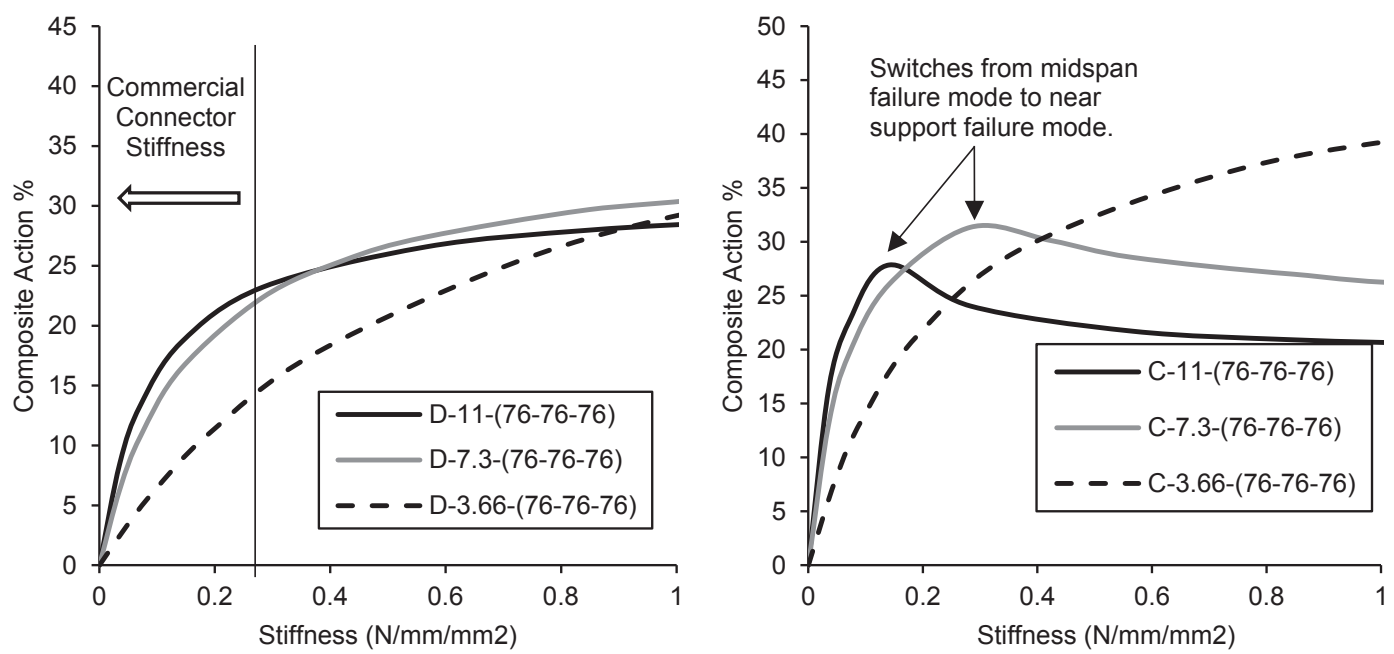

Fig. 16. Composite action as a function of connector stiffness in a SWP with a lumped connector distribution: (a) deflection and (b) cracking moment. 
For the sake of comparison, the same panel properties used in the previous two sections were used in this BSM as well. The stress profile shown in Fig. 14a is similar to what one would expect from a fixed-fixed beam than a simply supported beam due to lumped connector stiffness near the ends. This indicates that there could be panel cracking near the ends of the member with this configuration. Fig. 14b indicates the connector force distribution is very different than the well-distributed forces in previous configurations.

To further illustrate the effects of lumped shear stiffness and the versatility of the BSM, the following comparison is made to tests with solid sections. In 1994, Bush and Stine [37] tested the P-NCF panel which had two concrete $305 \mathrm{~mm} \times 305 \mathrm{~mm}$ squares at each panel end for handling and stripping in addition to truss connectors. The solid concrete sections were modeled as fully rigid links in the BSM, while truss connectors were modeled using values from the literature [27]. The high shear stiffness of the concrete solid sections led to a high shear force at the edges, causing the panel to crack there rather than the middle as would be expected. The BSM revealed that the panel behaved as if it was non-composite from the edge of the panel to the concrete solid sections, and as if it were partially composite between the concrete solid sections as shown in Fig. 15. This confirms the findings of Bush and Stine according to their calculations and strain gauge results [37].

As can be seen from plots of the cracking and deflection composite action versus stiffness (Fig. 16), the cracking composite action increases with an increase of stiffness to a certain extent. Once the lumped connector stiffness becomes large enough, the panel switches from a typically assumed positive moment midspan flexural failure to a nearsupport negative moment flexural failure at the lumped connector location, similar to that observed in Figs. 14 and 15. This is manifested in Fig. 16 by an apparent drop in composite action.

\section{Conclusions}

Currently many composite connector manufacturers use a matrix model approach, like the BSM introduced herein, to predict elastic SWP behavior. Analysis and design of partially composite SWPs has resided outside of codified documents since their advent, and these matrix methods are currently the closest thing to a uniform standard practice in the United States. The purpose of this paper is to quantify the accuracy of such a model in a uniform manner. The generalized BSM was introduced for prediction of the flexural performance of partiallycomposite concrete and rigid foam SWPs. The BSM models the concrete wythes using beam elements and shear connectors using linking (spring) elements. The properties of the beam elements are determined from the wythe geometry and the experimentally-determined modulus of elasticity and modulus of rupture of the concrete. The linking element stiffness is assigned the experimentally-determined connector shear stiffness, and is often available in the literature or from a manufacturer. The primary benefits of the model are its simplicity and versatility, making it suitable for design. Its accuracy was established in this paper and found to be similar to that of other methods related to strength and cracking of concrete members. These results indicate that this BSM, or the very similar methods that are already standard practice, provides an adequately safe elastic analysis. The following conclusions are made regarding the experimental and analytical portions of this paper:

1. BSM predictions were compared to experimental observations for more than 51 panels reported in the literature. Experimental observations of panel out-of-plane stiffness were between 74 and $135 \%$ of BSM predictions. On average, the BSM predicted out-of-plane stiffness within $3 \%$ with a COV of $17 \%$. This was comparable to other model predictions of various phenomena from the literature.

2. Using $7.5 \sqrt{f_{c}^{\prime}}$ as the modulus of rupture, the BSM was able to predict cracking to within $2 \%$ with a $\mathrm{COV}$ of $7 \%$. This is comparable to the predictions reported for tilt-up panels using $5 \sqrt{f_{c}^{\prime}}$ [33]. Similarly, predicting the deflection at cracking was predicted to within $2 \%$ with a COV of $18 \%$. This indicates that the current practice [4] of precast engineers using $7.5 \sqrt{f_{c}^{\prime}}$ in the BSM is appropriate given the available data.

3. The above two points indicate that the standard practice within the industry of using a matrix analysis method, such as the generalized BSM, is safe, appropriate and similar to other common analysis techniques for various limit states in the literature for engineered structures.

4. The BSM was shown to be robust enough to handle typical geometries and connector types and is able to predict large-scale elastic behavior.

5. Using the BSM, a parametric study was performed to demonstrate the effect of panel length on percent composite action in SWPs with uniformly distributed connectors, triangularly distributed connectors, and connectors concentrated at panel ends. Composite action increased with panel length, as expected, based on analytical and experimental evidence. Triangular and concentrated connector distributions were shown to be more efficient than uniform connector distributions.

6. Panels with global positive bending can fail locally at the end of the panel in negative bending if connectors are lumped at the ends. This was demonstrated with both the BSM and from the literature.

7. Plots of composite action as a function of connector stiffness were presented for several connector distributions and panel lengths, and can be used as a rudimentary design tool to preliminarily estimate SWP performance for any arbitrary proprietary connector.

\section{Appendix A. Supplementary material}

Supplementary data to this article can be found online at https:// doi.org/10.1016/j.engstruct.2019.109533.

\section{References}

[1] Al-Rubaye S, Sorensen T, Olsen J, Maguire M. Evaluating elastic behavior for partially composite precast concrete sandwich wall panels. PCI J 2018;63:71-88.

[2] Al-Rubaye S, Sorensen T, Maguire M. Investigating composite action at ultimate for commercial sandwich panel composite connectors. Cleveland, OH: PCI/NBC; 2017.

[3] Maximos HN, Pong WA, Tadros MK. Behavior and design of composite precast prestressed concrete sandwich panels with NU-Tie. Lincoln, NE: University of Nebraska; 2007.

[4] Losch ED, Hynes PW, Andrews Jr. R, Browning R, Cardone P, Devalapura R, et al. State of the art of precast/prestressed concrete sandwich wall panels. PCI J 2011;56(2):131-76.

[5] Gombeda MJ, Trasborg P, Naito CJ, Quiel SE. Simplified model for partially-composite precast concrete insulated wall panels subjected to lateral loading. Eng Struct 2017;138:367-80. https://doi.org/10.1016/j.engstruct.2017.01.065.

[6] Bunn WG. CFRP grid/rigid foam shear transfer mechanism for precast, prestressed concrete sandwich wall panels. Raleigh, NC: North Carolina State University; 2011.

[7] Frankl BA, Lucier GW, Hassan TK, Rizkalla SH. Behavior of precast, prestressed concrete sandwich wall panels reinforced with CFRP shear grid. PCI $J$ 2011;56(2):42-54. https://doi.org/10.15554/pcij.03012011.42.54.

[8] Woltman G, Tomlinson D, Fam A. Investigation of various GFRP shear connectors for insulated precast concrete sandwich wall panels. J Compos Constr 2013;17(5). https://doi.org/10.1061/(ASCE)CC.1943-5614.0000373.

[9] Bai F, Davidson JS. Analysis of partially composite foam insulated concrete sandwich structures. Eng Struct 2015;91:197-209. https://doi.org/10.1016/j.engstruct. 2015.02.033.

[10] Tomlinson D, Fam A. Analytical approach to flexural response of partially composite insulated concrete sandwich walls used for cladding. Eng Struct 2016;122:251-66.

[11] Tomlinson D, Fam A. Analysis and parametric study of partially composite precast concrete sandwich panels under axial loads. J Struct Eng 2016;142(10):04016086.

[12] Pozo-Lora F. On thermal bowing of concrete sandwich wall panels with flexible shear connectors. Utah: Utah State University; 2018.

[13] Pozo-Lora F, Maguire M. Thermal bowing testing of precast concrete sandwich wall panels. Utah: Utah State University; 2019.

[14] Joseph JDR, Prabakar J, Alagusundaramoorthy P. Insulated precast concrete sandwich panels under punching and bending. PCI J 2019;64(2):68-79.

[15] Elkady M, Tadros MK, Lafferty M, Morcous G, Gremel D. Precast concrete corbels for insulated wall panels. Concr Int 2015;37(10):45-50. 
[16] Henin E, Morcous G, Tadros MK. Precast/prestressed concrete sandwich panels for thermally efficient floor/roof applications. Pract Period Struct Des Constr 2014;19(3):04014013.

[17] Drysdale RG, Hamid AA, Baker LR. Masonry structures: behavior and design. Englewood Cliffs, NJ: Prentice Hall; 1994.

[18] Newmark NM, Siess CP, Viest IM. Tests and Analysis of Composite Beams with Incomplete Interaction. Proc of the Society of Experimental Stess Analysis. 1951.

[19] Pantelides CP, Surapaneni R, Reaveley LD. Structural performance of hybrid GFRP/ steel concrete sandwich panels. J Compos Constr 2008;12(5). https://doi.org/10. 1061/(ASCE)1090-0268(2008)12:5(570).

[20] Morcous G, Henin E, Lafferty M, Tadros MK. Design and testing of tornado-resistant precast/prestressed concrete sandwich panels with GFRP Ties. Salt Lake City, UT: PCI/NBC; 2011.

[21] Teixeira N, Tomlinson DG, Fam A. Precast concrete sandwich wall panels with bolted angle connections tested in flexure under simulated wind pressure and suction. PCI J 2016;61(4):65-83.

[22] Olsen J, Maguire M. Shear testing of precast concrete sandwich wall panel composite shear connectors. Nashville, TN: PCI/NBC; 2016.

[23] Olsen J, Al-Rubaye S, Sorensen T, Maguire M. Developing a general methodology for evaluating composite action in insulated wall panels. Chicago, IL: Precast/ Prestressed Concrete Institute (PCI); 2017.

[24] Al-Rubaye S, Sorensen T, Dorafshan S, Maguire M. Matrix model accuracy of partially composite concrete sandwich panels. Cleveland, OH: PCI/NBC; 2018.

[25] Robinson J, Hooks S, Lawson J. Verifying the Cause of Panel Cracking- A Case Study. Tilt-Up Today; 2017. 26 October.

[26] Hooks S, Robinson J. Shrinkage Cracking in Concrete Tilt-Up Construction. San Luis Obispo, CA: California Polytechnic State University; 2017.

[27] Naito C, Hoemann J, Beacraft M, Bewick B. Performance and characterization of shear ties for use in insulated precast concrete sandwich wall panels. J Struct Eng 2012;138(1):52-61. https://doi.org/10.1061/(ASCE)ST.1943-541X.0000430.

[28] Naito CJ, Hoemann JM, Bewick B, Hammons MI. Evaluation of Shear Tie Connectors for Use in Insulated Concrete Sandwich Panels. FL: Air Force Research Laboratory, Tyndall Air Force Base; 2009. doi:AFRL-RX-TY-TR-2009-4600.

[29] ASTM Standard E488-96. Standard test method for strength of anchors in concrete and masonry elements. ASTM International, West Conshohocken, PA; 1996. http:// doi.org/10.1520/E0488-96.

[30] ICC-ES Acceptance Criteria AC320. Acceptance criteria for fiber-reinforced polymer composite or unreinforced polymer connectors anchored in concrete. International code council (ICC) evaluation service, LLC., Washington, DC; 2015.

[31] ACI Committee 318. Building code requirements for structural concrete, Farmington Hills, MI: American Concrete Institute; 2014.

[32] ACI-SEAOSC Task committee on slender walls. Test report on slender walls. Structural engineers association of southern california, Whittier, CA; 1982.

[33] Lawson JW, Lai J. Concrete Slender Walls- Back to the Future. SEAOC 1010 Convention Proceedings. CA: Indian Wells; 2010.

[34] Salmon DC, Einea A, Tadros MK, Culp TD. Full scale testing of precast concrete sandwich panels. ACI Struct J 1997;94(4):354-62. https://doi.org/10.14359/486.

[35] Naito CJ, Hoemann JM, Shull JS, Saucier A, Salim HA, Bewick BT, Hammons MI. Precast/Precast/Prestressed Concrete Experiments Performance on Non-load Bearing Sandwich Wall Panels. Panama City, FL: Air Force Research Laboratory; 2011. doi:AFRL-RX-TY-TR-2011-0021.

[36] Trasborg PA. Analytical and Experimental Evaluation of Precast Sandwich Wall Panels Subjected to Blast, Breach, and Ballistic Demands. Bethlehem, PA: Lehigh University; 2014.

[37] Bush TD, Stine GL. Flexural behavior of composite precast concrete sandwich panels with continuous truss connectors. PCI J 1994;39(2):112-21.

[38] Henin EEA. Efficient Precast/Prestressed Floor System for Building Construction. Lincoln, Nebraska: University of Nebraska; 2012.

[39] Nowak AS, Collins KR. Reliability of Structures. Boca Raton, FL: CRC Press; 2013.

[40] Al-Delaimi YTM. Probabilistic Approach for Design Optimization of Prestressed Girder Bridges Using Multi-Purpose Computer-Aided Model. Ottawa: University of Ottawa; 2017.

[41] Paczkowski P. Serviceability Criteria for Decompression in Prestressed Concrete Bridge Girders. Lincoln, NE: University of Nebraska; 2009.

[42] Xu T, Castel A, Gilbert RI. On the reliability of serviceability calculations for flexural cracked reinforced concrete beams. Structures 2018;13:201-12. https://doi.org/10 1016/j.istruc.2018.01.001.

[43] Holmberg A, Plem E. Behavior of Load-bearing Sandwich-type Structures. Stockholm: Statens Institut for Byggnadsforskning; 1965.

[44] Chapman JC, Balakrishnan S. Experiments on composite beams. Struct Eng 1964;42(11):369-83.

[45] Bai F, Davidson JS. Theory for composite sandwich structures with unsymmetrical wythes and transverse interaction. Eng Struct 2016;116:178-91. https://doi.org/ 10.1016/j.engstruct.2016.02.052. 